\title{
Personal Artifact Ecologies in the Context of Mobile Knowledge Workers
}

\author{
Mohammad Hossein Jarrahi ${ }^{1}$, Sarah Beth Nelson, and Leslie Thomson \\ School of Information and Library Science, University of North Carolina at Chapel Hill
}

\begin{abstract}
Recent work suggests that technological devices and their use cannot be understood in isolation, and must be viewed as part of an artifact ecology. With the proliferation of information and communication technologies (ICTs), studying artifact ecologies is essential in order to design new technologies with effective affordances. This paper extends the discourse on artifact ecologies by examining how such ecologies are constructed in the context of mobile knowledge work, as sociotechnical arrangements that consist of technological, contextual, and interpretive layers. Findings highlight the diversity of ICTs that are adopted to support mobile work practices, and effects of individual preferences and contextual factors (norms of collaboration, spatial mobility, and organizational constraints).
\end{abstract}

Author Keywords: Artifact ecology; mobile knowledge worker; nomadic work; mobile technology.

\section{INTRODUCTION}

Weiser (1993) envisioned interactions with multiple systems interconnected by a ubiquitous infrastructure. One of the primary outcomes of ubiquitous computing has been a computational environment wherein users interact with multiple devices and interfaces. Consistent with this vision, users now interact with a growing number of devices and technologies in a technological environment characterized by trends such as the Internet of Things (Jokela, Ojala, \& Olsson, 2015; Santosa \& Wigdor, 2013). People's everyday environments are flooded by digital artifacts and platforms; many own, have access to, and make use of multiple information and communication technologies (ICTs) in their personal and professional lives, including laptops, tablets, and smartphones (Hamilton \& Wigdor, 2014; Stolterman, Jung, \& Will, 2013). New devices exist in an overlapping information space with traditional computers, including communication tools, cloud services, and social media. None subsist or are used in isolation (Baumer et al., 2012; Bødker \& Klokmose, 2012; Bossen \& Markussen, 2010; Stolterman et al., 2013; Turner, Qvarfordt, Biehl, Golovchinsky, \& Back, 2010). Recent human-computer interaction research has presented the concept of a "device" or "artifact ecology" as a means of accounting for the emerging computing environment in a "post-PC" era (e.g., Bødker, Korsgaard, \& Saad-Sulonen, 2016; Jarrahi \& Sawyer, 2012; Jung, Stolterman, Ryan, Thompson, \& Siegel, 2008; Vasiliou, loannou, \& Zaphiris, 2015), and suggests that artifacts and their affordances cannot be understood separately. Rather, these are meaningful only in relation to one another and to the ecology itself (Dearman \& Pierce, 2008; Houben, Tell, \& Bardram, 2014; Pipek, Wulf, \& Johri, 2012).

The proliferation and consumerization of ICTs has also contributed to the rise of new working arrangements, such as remote or mobile working. With the ubiquity of digital infrastructure, many knowledge workers, in particular, are now able to work almost anywhere, anytime (Blatt \& Gallagher, 2013; Davis, 2002). A recent survey by Forrester Research confirms that mobile knowledge work is on the rise: across Europe and the United States between 2001 and 2012, the population of mobile knowledge workers (MKWs) grew from 15

${ }^{1}$ Corresponding author; email: jarrahi@unc.edu 
to 29 percent (Brodkin 2013). Current research on MKWs' work practices highlights the physical mobility of these individuals: many may not have a centralized organization of which to speak, but instead orbit around clients and colleagues and through an extended professional network (Costas, 2013; Czarniawska, 2004). Their looser affiliations and higher degrees of autonomy make it difficult if not impossible for them to connect to "formal" computational resources in the same ways as those who work under the traditional paradigm can, for whom such things as hardware, software, systems, applications, standards, and policies are supplied and dictated (Erickson \& Jarrahi, 2016). Rather, MKWs face a persistent reality of mobility across spaces, times, organizations, projects, and other borders; their work tools must be able to withstand this and to work independently of a centralized system or structure, since intra-company virtual access or even standard connectivity may become unexpectedly unavailable (Oulasvirta \& Sumari, 2007; Perry \& Brodie, 2006; Su \& Mark, 2008).

Independence from physical organizational nuclei can be a source of both opportunity and challenge. MKWs may possess higher levels of flexibility (e.g., temporal, spatial, and technological), but not have the same access to organizational support as can be found in traditional office arrangements. This requires adept 'mobilization work' on the parts of MKWs themselves (Perry \& Brodie, 2006) -that is, extra activities and planning for spatial mobility and temporal shifts. More specifically, when it comes to the use of multiple technologies, MKWs have to embark on extra 'configuration work,' a type of meta-work required to understand, manage, and use information, applications, and services distributed across devices (Houben et al., 2014).

Performing work activities across devices and using different applications in organizational environments poses nontrivial challenges (Dearman \& Pierce, 2008; Oulasvirta \& Sumari, 2007; Santosa \& Wigdor, 2013). For example, many workers employ multiple devices to perform and support their work tasks, but find that design inflexibilities mean their information and activities remain fragmented between them (Bergman, Beyth-Marom, \& Nachmias, 2006; Dearman \& Pierce, 2008; Hamilton \& Wigdor, 2014). Conducting work in motion and from a range of locations exacerbates this issue (Oulasvirta \& Sumari, 2007; Santosa \& Wigdor, 2013), since workers have to constantly identify new infrastructures and grapple with a lack of transparency, interoperability, and control (Erickson \& Jarrahi, 2016; Perry \& Brodie, 2006).

Mobile working arrangements thus present an extra layer of uncertainty and complexity, complicating the way that artifact ecologies are constructed by individuals and employed to support their mobile knowledge work, requiring significant physical effort and planning for technological use (Jokela, Ojala, \& Olsson, 2015; Oulasvirta \& Sumari, 2007). The composition of artifact ecologies is closely related to the context of use, and the functional compatibilities of technologies are defined based on the particularities of each context (Jung et al., 2008; Stolterman et al., 2013). Given the rising importance of a diversity of digital technologies in enabling-and constraining-mobile work practices, there is a need for research that investigates artifact ecologies in these contexts. As we will note in the Related Work section, most research on ICT mediation in mobile work has primarily focused on the affordances of isolated technologies, and offers little insight into how multiple ICTs collectively support mobile work practices, as a part of a larger whole (or an ecology).

This study also contributes to current conceptualizations of artifact ecologies that draw attention to webs of work tasks and activities (e.g., Bødker \& Iversen, 2002; Houben et al., 2014). Even though activities can reflect some aspects of the sociotechnical context within which they are performed, a narrow preoccupation with micro activities may fall short of capturing broader organizational and contextual influences (Avgerou, 2008; Monteiro, Pollock, Hanseth, \& Williams, 2012). A recent study by Bødker et al. (2016) has begun expanding this narrow purchase of context by investigating the interplay between community spaces and artifact ecologies. This paper continues to advance this discourse by highlighting the way in which contextual 
influences shape artifact ecologies beyond the activity level. It therefore extends previous formulations of artifact and device ecologies, which tend to represent the context of technology use predominantly through the lens of micro activities.

In order to contribute to the literature of mobile knowledge work, and artifact and device ecologies, this study seeks to explore how MKWs combine multiple digital artifacts (hardware, software, and network connectivity) in order to address the contingencies of their dynamic working context. Its central research questions are:

- What constitutes an artifact ecology in the context of mobile knowledge work?

- How are artifact ecologies shaped by the contextual forces that define the work of MKWs?

- How does spatial mobility specifically impact the artifact ecologies of MKWs?

\section{RELATED WORK}

\section{Ecological Perspective}

As the technological landscape of users has become increasingly populous, recent research has witnessed a growing interest in the relationships among various digital artifacts from an ecological perspective. Researchers have borrowed the concept of ecology from Gibson (1977) to establish the way in which a multiplicity of tools and devices shape our computing environments. Gibson, a perceptual psychologist, argues that when interacting with their environments, animals and people do not perceive an object independently from its affordance(s) or from the physical world with which it interacts.

Several studies employ the idea of a "communicative ecology" to describe how people use multiple ICTs as part of a broader ecology for their communication needs (e.g., Gonzales, Fiesler, \& Bruckman, 2015; Johri, 2011; Memarovic, Langheinrich, Rubegni, David, \& Elhart, 2012; Turner et al., 2010). Turner et al. (2010) have used this framework to shed light on how the introduction of new ICTs in the workplace is (or is not) influenced by existing tools. Other studies using the communicative ecology framework suggest that no single ICT offers all the functionality that is needed for work and life, forcing people to balance a variety of dimensions in considering which tools they use to meet their communication needs (Jarrahi \& Sawyer, 2012; Zhao, Lampe, \& Ellison, 2016).

Another stream of research inspired by the ecological perspective explores interactions among physical devices and digital artifacts in an "artifact ecology" (e.g., Bødker et al., 2016; Dittmar \& Dardar, 2015; Erkut \& Serafin, 2016; Stolterman et al., 2013; Vasiliou et al., 2015). The term is used to embrace the ways in which users, as individuals or collectives, interact with multiple technologies, applications, and devices, appropriating different constellations for different purposes (Bødker \& Klokmose, 2012; Coughlan et al., 2012; Jung et al., 2008). Jung and colleagues (2008) define an artifact ecology as encompassing the devices "that a person owns, has access to, and uses." Rossitto and colleagues (2014) make a similar reference to "constellations of technologies" that integrate the diverse artifacts and applications that students use in their collaborative work, the composition of which depends on emergent needs.

The literature on artifact ecologies provides useful insights into the challenges of multi-device environments, the reality for many individuals today (e.g., Crabtree \& Rodden, 2008; Dearman \& Pierce, 2008; Jokela, Ojala, Grassel, Piippo, \& Olsson, 2015; Santosa \& Wigdor, 2013). Houben and colleagues (2014) list these as challenges: (a) managing one coherent work activity across several devices; (b) aggregating and pairing devices; (c) getting a clear model of what role a device plays in a multi-device setup; and (d) managing resources across multiple devices. In particular, managing information across different devices is a major challenge, as users have to constantly decide where to store their work information and how to transfer it 
and share it with others (Bardram, 2009; Hamilton \& Wigdor, 2014; Jokela, Ojala, \& Olsson, 2015). Santosa and Wigdor (2013) note that cloud-based synchronization tools and web applications have offered partial solutions to this problem, but that information is still fragmented across devices and cloud services.

Individuals often come up with creative workarounds to these challenges, putting together a patchwork of tools and tactics such as manual synchronization, mirroring between devices, or e-mailing important items to themselves (Jokela, Ojala, \& Olsson, 2015). In short, employing multiple devices to perform a set of work activities requires significant effort and 'configuration work' (Houben et al., 2014) on the part of individuals, as they attempt to set-up, understand, and use a number of tools, applications, and services. One of the root causes of this is that tool- or document-centric design approaches center on applications and files and not on the activities of users, leaving little support for more complex workflows (Dearman \& Pierce, 2008; Houben, Bardram, Vermeulen, Luyten, \& Coninx, 2013). Communicative and artifact ecologies build from activity-based computing, foregrounding the ways in which users recurrently enact devices and recognizing that people increasingly engage in activities that span them (Bødker \& Klokmose, 2012; Santosa \& Wigdor, 2013). Its primary objective is therefore to support individuals' activities rather than the resources and tools that are used to perform these activities (Bardram, 2009; Bardram, Jeuris, \& Houben, 2015).

Previous research tends to define ecologies based on their arrangement or constellation of technologies, and by the activities supported across them. For example, Jung and colleagues (2008) study how participants distribute their activities across different artifacts, and how the role of artifacts defines the affordance of other artifacts in the ecology. Vasiliou and colleagues $(2014 ; 2015)$ consider interactions among collaborative activities, information flow, and multiple artifacts by adopting the distributed cognition model. Crabtree and Rodden (2008) discuss the relationship between ubiquitous technologies and users' activities, foregrounding the collaborative articulation activities that cut across several devices and marry digital and physical environments. Similarly, activity-based computing centers on identifying and establishing links between multiple device use and activities, explicating the role of devices in overall workflow and information management. For example, Houben and colleagues (Bardram et al., 2015; Houben et al., 2013) focus on collaborative activities not typically supported by desktop interfaces, and propose an activity-based system that facilitates the coordination of work activities across several devices.

This analytical attention to interdependencies between activities and technologies can be considered an instance of what Monteiro and colleagues (2012) call the 'here and now' focus of CSCW research (p. 582), and it may overshadow broader contextual examinations. In representing a web of activities, some artifact ecology research has included aspects of context, such as personal (e.g., Dittmar \& Dardar, 2015; Stolterman et al., 2013) or collaborative dimensions (e.g., Houben et al., 2013; Oleksik, Milic-Frayling, \& Jones, 2012) of users' activities. We extend this work by integrating multiple layers of the context within which activities are supported by artifact ecologies, and thus offer a more nuanced understanding of work context and its influence on how artifact ecologies support work activities.

\section{Mobile Knowledge Work}

The primary work outputs of many knowledge workers are intangible, analytic, creative, and-oftentimes today-digital in nature (Schultze, 2000). Given this, contemporary knowledge work positions typically afford an option for individuals to 'go mobile' (Davis, 2002; Rainie \& Wellman, 2012). Historically, work was defined primarily by its "atom" or manufacturing nature (Barley, 1986), identified by the processing and production of large-scale physical items. Now, however, the United States is fast being defined by its dominance in "bit" or knowledge work, being the creation and manipulation of ideas or data (Rainie \& Wellman, 2012). Unlike earlier, more mechanistic forms of work, most knowledge work is project- rather than function-based (Barley 
\& Kunda, 2006; Schultze, 2000); thus, it is easily unstrapped from specific locations, provided the appropriate technology is available (Costas, 2013; Olson \& Olson, 2014).

The location-independent nature of knowledge work, together with the enabling role of ICTs, has given rise to a growing population of workers who are not tied to single locales, and who conduct work, for example, in coffee shops, co-working spaces, and airport lounges. MKWs are largely location-independent, spatially mobile, and defined by their nomadic work practices (Chen \& Nath, 2008; de Carvalho, Ciolfi, \& Gray, 2011; Su \& Mark, 2008). Mobility, both in relation to knowledge work and otherwise, has also been extensively researched in recent decades (e.g., Costas, 2013; Cousins \& Robey, 2005; Ling \& Donner, 2009; Middleton, 2008; Sørensen, 2011). Scholarship related to mobile work practices and professions from within management studies has mainly focused on concepts such as temporary work and nomadic work, investigating how well-defined understandings of space, time, context, and traditional organizational norms and structures are being upended for new, more flexible arrangements variously instantiated across telecommuting, home-working, co-working, shared offices, hot-desking, and mobile working forms (e.g., Bardram \& Bossen, 2005; Büscher, 2013; Fulton, 2005).

Human-centered computing researchers have led investigations into how ubiquitous infrastructures and mobile technologies shape the extension and expansion of knowledge work outside of the conventional office (e.g., Büscher, 2013; Ciolfi \& de Carvalho, 2014; Czarniawska, 2014; Jarrahi \& Thomson, 2017; Liegl, 2014; Perry, 2007; Rossitto et al., 2014). Popular themes in this body of work include planning and preparation needed for conducting work mobile-ly (i.e., mobilization work) (e.g., Bardram \& Bossen, 2005; Perry \& Brodie, 2006); the use of digital technologies for professional nomadism (e.g., de Carvalho et al., 2011; Su \& Mark, 2008); and the extension of work into the home environment (e.g., Czarniawska, 2014; Middleton, 2008). One of the focuses of past literature on nomadic or mobile work has been the ways in which workers handle the challenges posed by multiple local and ubiquitous digital infrastructures (e.g., Erickson \& Jarrahi, 2016; Su \& Mark, 2008). Studies have examined the unique ways that mobile workers come to grips with the security and privacy implications of various nonproprietary technologies, for example. Oulasvirta and Sumari (2007) suggest that workers may distribute their data across different devices in order to lower the possibility for unwanted parties to access it. Other mobile workers may avoid working in certain public spaces over concerns about the privacy of their work-related communications (Su \& Mark, 2008).

This paper extends the scholarship on mobile or nomadic work with an empirically grounded example of how multiple ICTs are brought together in artifact ecologies to support mobile work practices. Mobile knowledge work is an especially interesting context in which to consider artifact ecologies because it exposes the triadic interdependencies between knowledge work, mobility, and use of multiple digital technologies. Over the past decade, increasing attention has been paid to how ICTs enhance the physical mobility of work (de Carvalho, 2014; de Carvalho et al., 2011; Su \& Mark, 2008). Despite insights being generated about the mediational roles played by ICTs, these studies, with few exceptions (e.g., Oulasvirta \& Sumari, 2007; Rossitto et al., 2014) tend to dwell on the relationship between the use of isolated technologies and mobile work practices. For example, many investigate how the use of mobile devices underlies the mobility of work (e.g., Axtell, Hislop, \& Whittaker, 2008; Beurer-Zuellig \& Meckel, 2008; Brown \& O'Hara, 2003; Hislop \& Axtell, 2011; Ludwig, Dax, Pipek, \& Randall, 2016; Perry, 2007; Väätäjä, 2012), which may gloss over the multiplicity of technologies used in mobile work and the activities that take place across technologies. The vast majority of mobile workers - and workers in general-employ suites of devices, tools, and technologies in their daily work (de Carvalho et al., 2011; Rossitto et al., 2014). Because of this, there is a need for empirical inquiry that looks beyond the use of single technologies in mobile work situations within an ecological and holistic framework. 


\section{METHODOLOGY}

Our sample consisted of 36 MKWs, mostly drawn from North Carolina's Research Triangle, most of whom were either self-employed or contracted by different companies and clients. They represented diverse knowledge work domains, including business and strategy consulting; higher education; web and user experience design; communication and content management; IT support; real estate; and legal services. The diversity of our sample impacted our findings, as we observed practices that support various types of mobility, from working in multiple locations over the course of a single day to working from multiple cities in the course of a week. These different practices entailed different types of technology use.

Data was gathered via in-depth, semi-structured interviews with all participants and the additional collection of research diaries from 13 of the same participants. Participants were chosen for inclusion based on their engagement in knowledge work; the mobility in their work; and the centrality of mobile practices to their work. Knowledge work involves the creation or transmission of high-level information, is intellectual and creative, and requires both theoretical and technical skill and a formal education (Schultze, 2000). Lilischkis (2003) proposed four categories of mobile workers, which we used to judge and select participants: On-site movers engage in work that requires movement around a specific site; Yo-yos occasionally work away from a fixed location, in a temporary workplace; Pendulums alternate between two different fixed locations such as an office and home, with relatively equal distribution; and Nomads perform work at changing locations, moving from one to the other.

Initially, sampling was purposive. Later, snowball sampling was used to increase our sample size, and theoretical sampling was used to target certain types of MKWs-specifically, those with high levels of mobility (Nomads). Participants ranged in age from their mid-twenties to mid-sixties, and all had fairly high levels of technical competence, as this was integral for their work. In interviews, participants discussed their work tasks and workspaces, the tools they used to do their jobs, and their strategies for being effective mobile knowledge workers. Interviews lasted 50 to 90 minutes and were audio recorded and transcribed.

Diary data was collected from 13 of the original 36 participants who were considered especially mobile, and therefore of particular interest. That is, for this portion of the study, we sought out participants with higher, more extreme, nomadic levels of between- and within-day spatial mobility. The use of diaries allowed for insitu data collection about mobile knowledge work, technology use, and work space, and provided further insight into participants' practices in naturalistic settings over a longer period of time (Grinter \& Eldridge, 2001). Interview data may be susceptible to recall bias; therefore, the diaries provided useful additional information, with the data being collected as close to the unfolding of events and practices as possible. The work day of a mobile knowledge worker involves frequently shifting social and spatial environments (Ciolfi \& de Carvalho, 2014), making direct researcher observation difficult. Participants were able to complete the diary entries from any location and any device. The diary questionnaire (a mix of multiple-choice and openended questions) was emailed to participants twice a day for 7-10 days. Participants were asked to complete both diary entries per day during the duration of the study and were able to submit them through online survey software. Participants were compensated $\$ 3$ per entry, given by gift card after the completion of the diary collection (e.g., 2 entries per day for 7 days $=\$ 42$ gift card).

Data collection and analysis proceeded concurrently. NVivo research software was used to facilitate analysis. Between August 2015 and Dec 2016, the first two researchers engaged in successive rounds of transcript reading, memo writing, and extended conversation to become familiar with the collected data and collaboratively 'sense-make' the initial insights presented here. 


\section{FINDINGS}

Our analysis centers on artifact ecologies as encompassing both the technological environment (hardware, software, and network infrastructures) and the social context of the digital environment. The artifact ecologies of MKWs are materially scaffolded, as they involve diverse ensembles of systems, tools, and connectivity that are sustained through the use of gateway technologies. These ecologies are not constructed in a vacuum but are contingent upon the unique sociotechnical context of MKWs, characterized by spatial mobility and relative independence from organizations (organizational contexts). These contextual factors present unique opportunities and challenges, which are reflected in MKWs' artifact ecology configurations. Configurations also reflect the personal knowledge and preferences of workers as well as the demands of collaborative context. Below, we discuss common contextual and technological characteristics of MKWs' artifact ecologies, and the ways overlapping contexts come to shape these ecologies (see Figure 1).

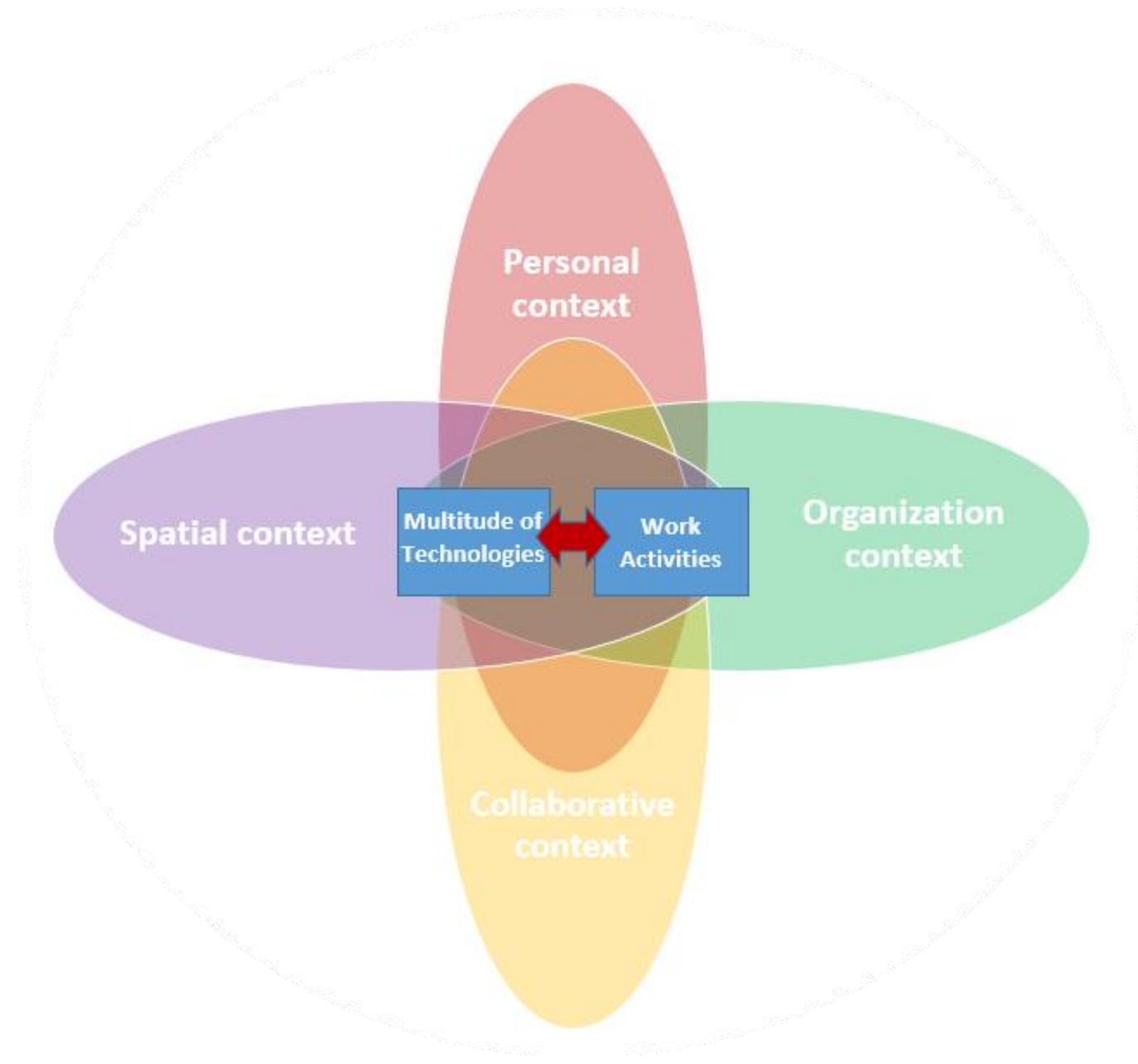

Figure 1. Artifact ecologies of MKWS shaped by multiple contextual factors. 


\section{Technological Diversity and Work Activities}

The artifact ecology around MKWs is characterized by a diversity of tools and technologies that they can leverage for different work activities. All the participants in this study used a combination of smart phones, tablets, and laptops to complete their work. On average, they used at least two devices on a daily basis, but some used as many as four devices within the same work day.

A vast majority of the MKWs interviewed still prefer to use desktop or laptop computers for certain types of work, the exceptions being three real estate agents and one salesman who enjoyed working on their mobile phones. P3 (a business consultant) elaborates: “My tablet is my flex device. I got it hoping that I wouldn't need my laptop anymore, but I do still need my laptop, and it's because I write too much. So even with the keyboard component there, it's not as easy to write documents, real documents, as it is with a real keyboard on a laptop." In a similar fashion, P18 (a software developer) still does not see his cell phone as the ideal device for some of his work practices. He says that "you can't code on your phone for instance," or do "checkins to GitHub." A mobile knowledge worker's ability to work from a mobile phone is influenced by the type of work being conducted.

Participants also used a diversity of applications and software that greatly enabled mobile work. P29 (a realtor) notes, "I think the adding of the apps have made me a lot more mobile [...] All the apps fit so perfectly in your phone [now]. Everything comes out perfectly on your app." Some apps and software were unique to specific work fields, and some used by all. Software such as Photoshop (graphic designer), support ticketing systems (IT support), Camtasia (multimedia content creator), GitHub (software developer), LibreOffice (content editors), and Multiple Listing Service Systems (real estate agents) were specialty, whereas others like most of those listed below were seen as common denominators of the artifact ecology, enabling mobile working arrangements.

For information management, cloud services play a key role in providing access to work resources across time and space. On the one hand, some participants use a variety of cloud services for storing, and retrieving work information without much concern. This could be due to the nature of their work and services they provide. As a public relations and communication strategist, P3 (a business consultant) made it clear why there was no issue employing Dropbox extensively: "I'm not concerned about it. Right now, I don't have any clients that have anything ultra, hush-hush that they're sharing with me. Remember, I'm the person whose job it is to tell everybody. So most of what I have isn't terribly quiet."

On the other hand, several participants raised concerns over the privacy and ownership of cloud-based data. For example, P15, an IT support worker, was hesitant to use cloud services for his work related data: "because they are third party or privately owned resources, there's always the question of ownership and licensing... So once it's up there it's up there for good; it's kind of like the whole Facebook mentality; once you post a picture it doesn't matter whether you take it down, it's there." A similar concern compelled P10 and P33 to draw upon less known but reportedly more secure cloud service such as Box Or SpiderOak to protect the privacy and security of sensitive data: "Dropbox is just [for] general stuff that I want to be able to access from everywhere, and then actually there's another service similar to Dropbox called SpiderOak, which basically works the same way but is more focused on privacy, they have a zero knowledge privacy policy and so I've decided all of my like daily files, but more sensitive things. So like all my client files, invoices, things like that are all in Spideroak because it has better protection" (P33).

Many participants also used external hard drives in addition to making automatic back-ups to cloud services, as this offered peace of mind regarding data availability. Another common practice observed among participants was diversification of the personal cloud services in their artifact ecology. This was partly due to 
concerns over loss of important data should one platform become inaccessible, leading them to copy the same document or file into multiple cloud services.

As independent workers, many of our participants were also required to serve as their own project managers, planning tasks and projects, and making sure that time management mechanisms were utilized to meet individual and collaborative project goals. Many of the participants used tools such as Basecamp, Toggl, Asana, and Trello for tracking time and managing individual and collective projects. In addition, they made great use of free communication apps such as Skype, Google Hangout, and Slack Talk to voice chat or video conference with others.

Not only did our participants use a diversity of applications accessed from multiple devices, but they often also used multiple applications with similar functions. Table 1 shows the number of participants who used one, two, three, or four or more devices, email accounts, cloud services, communication applications, and time, task, and project management applications.

\begin{tabular}{|l|c|c|c|c|}
\hline Devices, services and applications & $\begin{array}{l}\text { Number of } \\
\text { participants who } \\
\text { used 1 }\end{array}$ & 2 & 3 & 4 or more \\
\hline Devices (laptop, desktop, tablet, smartphone, etc.) & 3 & 11 & 11 & 11 \\
\hline Email accounts & 18 & 12 & 4 & 2 \\
\hline $\begin{array}{l}\text { Cloud services (Dropbox, Google Drive, OneDrive, } \\
\text { Crashplan, SpiderOak, etc.) }\end{array}$ & 7 & 12 & 8 & 7 \\
\hline $\begin{array}{l}\text { Communication applications (Skype, Google Hangout, } \\
\text { Slack, WebX, HipChat, etc.) }\end{array}$ & 6 & 10 & 9 & 5 \\
\hline $\begin{array}{l}\text { Time, task, and project management applications } \\
\text { (Asana, Basecamp, Workflowy, Todoist, Trello, etc.) }\end{array}$ & 10 & 12 & 2 & 2 \\
\hline
\end{tabular}

Table 1. Number of participants who used multiple devices, services, and applications.

\section{Gateway Technologies}

The variety of ICTs available at relatively low cost provides MKWs with technological flexibility. The artifact ecology around MKWs is diverse, addressing multiple work environments and various needs; however, a common problem caused by this diversity is a lack of interconnection and interoperability among various technologies.

Each technological provider, such as Google, Microsoft, or Apple, provides a relatively cohesive ecosystem with adequate interoperability among different devices and applications. For example, Google Sync ensures that all emails from Gmail, contacts, and calendars synchronize across different devices, but several of our participants found it difficult to coordinate their activities and information resources across different technology ecosystems. P3, a consultant, found it challenging to use Microsoft Outlook on her Android phone: "I actually have problems with calendaring right now, because I'm having trouble with making all the technologies work. [Android] wants Google Calendar to be your calendar. Google Calendar doesn't work well for me. I started getting really frustrated with how Google was taking over my data, and I just stopped." Disconnect between ecosystems occurs when it becomes difficult or challenging to create the device ecology of one's choice based on multiple technological platforms; each element of each ecosystem (e.g., Microsoft 
Outlook) often reinforces and imposes the use of specific other elements (e.g., mobile operating systems) from the same technology provider. P6, a technology columnist, emphasizes the same issue, which also happens to be centered on calendar use: "[My company] is standardized on Outlook, which I hate. I am doing all my appointments in Google Calendar. I asked 'How I can import Gmail Calendar into Outlook so I have one calendar?' And they said, 'Sorry, we can't help you, we don't support Gmail Calendar.'”

One technological solution that helps workers to ameliorate these gaps and thus sustain a workable artifact ecology is gateway technologies, which resolve the so-called 'Battle of the Systems' (David \& Bunn, 1988). Several participants used gateway tools to connect competing ecosystems. Applications such as IFTTT (If This Then That) create connections between apps and ecosystems like Facebook, Dropbox, and Gmail, as well as ubiquitous devices such as cellphones, Nest Thermostat, and wearable activity tracking technologies. As P26 (a freelance business writer) describes it, "IFTTT kind of automates different apps to work on your behalf," and he can "pull everything together with that app." Gateway technologies enable interoperability among incompatible systems and in so doing "make it technically feasible to utilize two or more components/subsystems as compatible complements or compatible substitutes in an integrated system of production" (David \& Bunn, 1988, p. 172). The difference with our way of applying the concept of gateway technology is one of scale: for MKWs, organizing gateways is done at the individual level, and less at the organizational or inter-organizational level. (Nevertheless, there remains a fierce allegiance to the larger cyberinfrastructure discourse in which these concepts were first introduced.)

\section{Personal Context (Individualization)}

Relative independence from an organizational sphere of influence enables MKWs to tailor their artifact ecologies to meet personal needs and unique forms of mobility. Independent of any need to remain in a singular place to carry out their work tasks, these workers may go to great lengths to configure numerous tools in individually and locally particular ways to ensure that their information resources are accessible. This is in line with research that suggests the configuration of artifact ecologies is influenced by personal context and objectives (e.g., Bødker \& Klokmose, 2012; Sørensen \& Kjeldskov, 2014). Jung and colleagues (2008, p. 209) note, "ecologies evolve according to individual users' personal strategies and appropriation of artifacts."

The individualized nature of the artifact ecology often translates into reliance on a single ecosystem with which workers are accustomed and comfortable after years of experience. Therefore, personal preferences for a certain brand or "device ecology" (Vertesi, 2014) greatly shapes the personal artifact ecology of mobile knowledge workers. P7 (a freelance business productivity consultant) has "always been a Microsoft girl" so her "biggest [cloud] thing is OneDrive." She prefers OneDrive to other cloud services simply because she has used Microsoft products for years. One of the reason that workers may find themselves attached to one ecosystem is the convenience of cross-device or cross-application interoperability. P21 (a freelance marketing consultant) notes, "I'm all Apple for a reason." Rather than forcing different brand ecosystems to talk to each other, he is happy sticking with one.

Even for those working for bigger organizations, device ecologies are still individualized. Most of these MKWs use multiple devices to keep a separation between their corporate activities and personal activities, which sometimes include freelance work. Individually organized and owned device ecologies may be intentionally disconnected from the infrastructures owned by organizations. P6 (a technology columnist) describes this strategy: "I sync my desktop computer to everything in Dropbox, but I only sync the MacBook air to my [company name] stuff. Because, [my company] owns this machine. I don't want them owning my data." A few participants, much like P6, purposefully disentangle and maintain a gap between their personal and organizational ICTs. 
We also found a strong sentiment among almost all the MKWs working for larger organizations that their company's work must stay on a specific work device. This strategy may hinder the mobility of the workers since, for certain long trips, they have to pack both personal and work laptops and other devices to address the separation of organizational and personal information resources.

The artifact ecologies that our participants create extend to, and blend with, their personal lives as well. P6 scans work-related items in order to digitize them, but his wife also got him into scanning "everything that comes into the house, every bill." P25 (a freelance technical writer) listens "to music all day every day," which is not necessary for her work, but creates a more pleasant work environment. She struggled to find the perfect music service/application, since "the more that they changed iTunes, the more I hated it. And I hated it a lot to begin with. So I switched from iTunes to Google Play, and it also sucked. But I started being my music with Google Play and finally, well, I use Pandora a lot. But just in the last couple of months I switched to Spotify because it's the best as far as I found so far. It's the best cross platform." Listening to preferred music helped several participants working from public places such as coffee shops as well; many noted that they regularly use noise-canceling headphones so to stay focused. While these are rather innocuous examples, they are nonetheless indicative of the work-life overlap with which MKWs continually contend (explored more in Jarrahi \& Thomson, 2017).

\section{Context of Collaboration}

Even though artifact ecologies are primarily constructed by each individual MKW, they are at the same time collective. That is, they can be used to share resources between heterogeneous groups of users, reflecting the preferences of multiple colleagues, contractors, and clients. In this way, artifact ecologies differ from the isolated use of multiple artifacts by individuals (Monteiro et al., 2012), since the configuration of artifact ecologies reflects the significant articulation work performed in order to address the needs of different projects and collaborations (Crabtree \& Rodden, 2008; Houben et al., 2013).

Many of our participants juggle multiple projects, and therefore may need to disregard their personal preferences in favor of easy collaboration with different clients and contracting organizations. P25 (a freelance technical writer) finds Google Drive organization and display counterintuitive, but uses it anyway because of client preferences. When P18 (a software developer) sets up a call with a client organization, he goes to the tool "where the people are," but laments about the sometimes "terrible software platforms" and the need to "suck it up." Bødker et al (2016) suggest that there may be tension when the intersection between multiple ecologies contradicts the personal preferences of participating members. In these scenarios, most collaborative articulation work ultimately ends up directed at ameliorating the fragmented interactions brought on by individual collaborator preferences (Crabtree \& Rodden, 2008). The same issues arise when participants share information and collaborate with family members on personal matters, whether from their work devices or not. For example, P4 (a knowledge management lead) uses Google Drive with her fiancé; "we share documents like invite lists and we work on planning stuff." Collaboration with family also involves compromise. P6 mentions: "My wife and I often disagree on what technology we prefer to use... She uses SugarSync instead of Dropbox, and Sky Drive or One Drive instead of Google Drive."

The cloud services used by MKWs connect the artifact ecologies of many collaborators working on the same project. Free cloud services such as Dropbox and Google Drive offer useful ways of sharing, managing, and tracking shared information resources even among co-workers in large organizations (when these organizations have relaxed technology policies). MKWs who operate as independent workers or freelancers may often find themselves members of a virtual team. Several tools allow them to stay updated about collaborative projects. For some, for example, using Slack is "just like the sitting in a big office but then kind 
of catching up with everyone in the common area to see okay what you've been doing, how things are, you know, but in a digital way" (P19, a freelance user experience designer). These tools allow collaborators to come together across great distances. P30 (a freelance business consultant) regularly uses Asana to share appointments with clients or anyone working for her. In P25's (a freelance technical writer) diary entries she noted instances in which she was "catching up on project progress with teammates in London and India via Slack and Jira."

One further issue that arose in our data, though not unique to MKWs, was the separation of personal and professional lives on social media. Except for a handful of participants who used Facebook to interact with work-related contacts, the vast majority employed this website solely for personal connections. For those who do use it to network professionally, it is a key component of their artifact ecologies, facilitating relationships with informal relations. Twitter was more commonly used to connect professionally, and to maintain potentially fruitful professional ties with weak ties.

\section{Spatial Context (Mobility)}

Spatial mobility shapes how MKWs construct their artifact ecology. Working from multiple workspaces requires awareness about local and non-local technological resources, and an awareness of how to best address spatial constraints. Taking advantage of local technological infrastructures is critical in mobile work. This is an instance of what Brown and O'Hara (2003) call "colonization" of spaces, or turning "third spaces" between home and work into workable workplaces.

One of the most important implications of working from various places is access to the Internet. Almost all participants used cellular data for some work related purposes; with the exception of 3, all used public WiFi when they could, and 15 have created hotspots on their smartphones for use in public places. Out of 36 participants, 16 noted they could still accomplish some aspects of their work even if not connected to the Internet, but another 16 admitted it was almost impossible to work without an Internet connection.

P30 (a freelance business consultant) discusses how she gets access to the Internet in different locales using different types of connections: "I have a mobile hotspot. I just turn on the data plan on my phone and then I can use my phone for WiFi and so my computer can pull from that. So if I know that I'm going to be traveling and there may not be easy internet, I will turn on the data plan so that my computer can get online using my phone and then I'll use free WiFi in various places, so I'll usually try to do some research to see who offers WiFi before I decide to go there." She clearly describes the extra activities (or mobilization work) that this use of cellular data may involve: "So whenever I'm using [cellular] data I turn off Dropbox syncing because it's just big files and stuff and then when I'm back on WiFi I turn Dropbox back on." P24 (an attorney at a small law firm) also connects to WiFi in multiple ways, describing them in his diary entries, "Public WiFi keeps dropping. Supplementing public WiFi with personal WiFi." Therefore, in many locations, hotspots created using the smartphones play a key role in providing the Internet access. This common practice among MKWs working from public places echoes a subtle understanding about the practical utility of publicly accessible WiFi, as mentioned by Sanusi and Palen (2008).

As noted earlier, working from public locations and using public infrastructures may pose concerns over security and privacy of information resources. Some of the participants working from public places abstain from using public WiFi connections even when they are reliable. For example, P10, a lawyer, was especially cognizant of clients' confidentiality; as a result, he used his data plan rather than free public WiFi and stored clients' information with Clio, an extra-secure cloud-based legal management system. P26 (a freelance business writer) described his security concerns of public WiFis: "When you're on, like, an open network WiFi and you just want to be extra cautious just knowing that it's really easy for people who know what they're 
doing so to sniff out a network and kind of get a sense for different data." To address this concern, P26 uses a USB-powered firewall that provides a secure use of WiFi in public locations and protection from intruders who may be monitoring traffic on a public network (Figure 2). In a similar fashion, P22 (freelance Internet marketer) takes advantage of an external wireless travel router to secure Internet connections and file sharing on public networks. P25, P33, P36 use VPN connections to secure transfer of sensitive information over a public network. P33 stated: "I read a couple of articles about how easy it is for somebody, like, sitting across from me at the café to be somehow monitoring what you're doing and I think about that quite a bit and so I'm very wary. But then if I'm at a café I might be trying to do everything that I have to do in a day. I definitely don't want to do that in a situation where there might be somebody who can capture any of that. I often will use the VPN just as kind of a way to add an extra level of security."

Personal and organizational preferences also reinforce the privacy of mobile work performed across various locales. P37 (a clinical research associate) noted: "I told my boss I would be probably working in a coffee shop and she was like, 'oh, you should probably get a privacy screen and it's a requirement of the company,' but I think a lot of people don't have them."

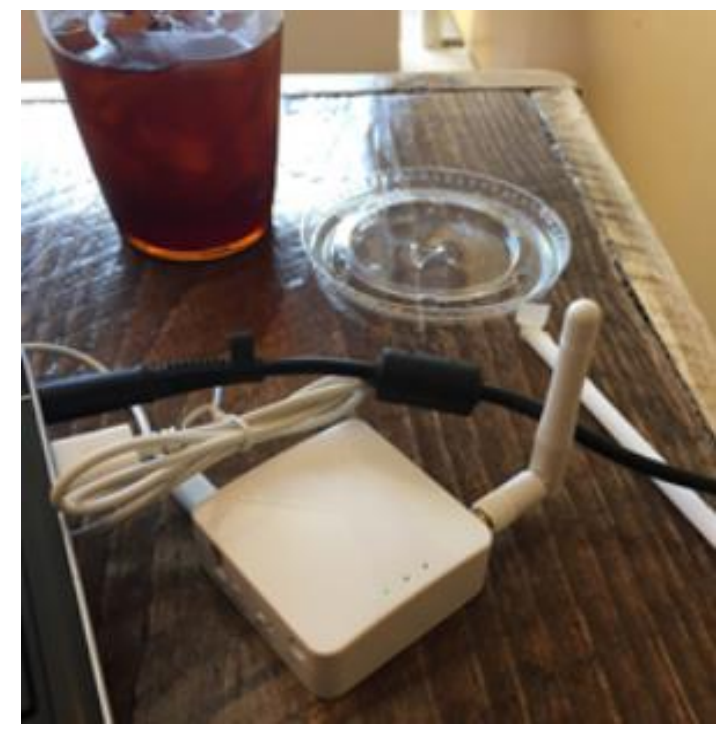

Figure 2. P26's mobile firewall/VPN device.

P15 (a IT support person working for a large organization) walks frequently across multiple buildings on a large campus, but surprisingly does not use the WiFi network on his phone. "I find consistency with 4G across whatever building I go to. We do have some dead spots within [my institution]. If you have the adaptor [for WiFi] on and it's not getting a signal it drains the battery pretty quickly. To conserve battery life and to maintain connectivity, I typically keep it on 4G." Using 4G ensures P15 remains connected and does not unnecessarily drain his battery.

Participants demonstrated innovative ways of leveraging public/free technological resources in different places. P22 (a freelance Internet marketer) occasionally works from academic libraries where he's "not allowed to install software on [the computers]. But I can still plug in this flash drive and launch the application which is set up to actually be run from a flash drive." He also uses an app that identifies the fastest WiFi in a neighborhood: "I've got on my phone an app that lists the WiFi networks in the area and it shows a graph showing the strength of the signal, and so I can just walk around the neighborhood and keep track of which network ID's I see. Whether they're open, whether they have a password on them, how strong the network 
is." This app has allowed P22 to learn where to find the best public internet connection, and therefore the best place from which to work.

MKWs have a unique, often unstable relationship with place and local resources, as they are not tied to standard work sites (Bardram \& Bossen, 2005; Brown \& O'Hara, 2003). Place is a concern for many; research (e.g., Brown \& O'Hara, 2003; Thomson \& Jarrahi, 2015) suggests that MKWs have much less physical certainty compared to office workers. For example, they cannot always take Internet access for granted. P31, a freelance web designer, needs to work offline when traveling abroad without a SIM card. "I made a point of finding versions that are available offline. Like, I have time tracking software that I use for some of my editing projects. And again, a lot of the fancy new ones are web based and if there's no Internet access the time tracking doesn't work. So I have a standalone application on my computer that has nothing to do with the internet, so I can track my time even if I'm offline." Because an occasional lack of Internet access is expected, some MKWs seek out programs that do not rely on it.

Gateway technologies can also help offline technologies communicate with online technologies. P31 (a freelance web designer) likes to use Asana for task management, but can only add tasks to Asana while online. "But I discovered Trello. Their app works offline. And so what I have set up with Zapier is I add a new task in Trello it automatically gets added to Asana once I'm back online." Zapier has essentially allowed P31 to make Asana work offline.

Finding a place to plug in can be challenging when MKWs perform work from public places like coffee shops. P7 (a freelance business productivity consultant) wrote in a diary entry that the biggest work challenge of the day was "Finding a table near an outlet to power my laptop at a very popular Starbucks. It's a game of patience." A few of our participants work regularly from coworking spaces, which have many of the amenities of a traditional office space. Several participants noted coworking spaces in the US and other countries are changing the way MKWs work while traveling. P19 (a freelance user experience designer) plans trips in such a way that she can take advantage of these coworking spaces and have access to physical and technological resources such as whiteboards and large monitors while traveling abroad.

Virtually all of our participants always have on hand various chargers and cables that help them keep their devices powered. Among the contents of her work backpack, P25, (a freelance technical writer), lists both a "power cable" and a "USB charger." P9 (a freelance speaker) carries "an electrical splitter that splits the plug into 3 plugs, and I carry it in my bag in case I'm in an airport or in a Starbucks and all the plugs are filled. I can split the plug and make 3 outlets."

A common situation for MKWs is working on the move and during transit. Participants use various tactics and multiple technologies to turn this dead time into a productive work opportunity. As a result, voice recognition technologies occupy a unique place in the artifact ecology of MKWs. Many of our participants work while literally on the go, as they are driving from one location to another. They may speak to clients or colleagues on the phone while they drive, but have also found other ways to get work done. Voice function on their phones can read emails to them, and voice recognition can make notes or create task lists for them. P3 (a business consultant) sums up the major benefit of voice recognition as "I need to not be looking at a screen." As another example, P5 (a freelance web designer) continues working on web development projects while sitting on the passenger seat and using local webservers on his laptop even without access to the Internet. Other participants commonly find ways to take advantage of transit time in the train or on the plane. Some participants (e.g., P25 and P33) reported working WiFi networks on the train, while many find airplane time (particularly on long flights) very useful time to engage in focused work. P13, as a software engineer, founds create workarounds to develop web pages and leverage an online web server without having to pay for the Internet: "All those in flight Wi-Fi services redirect continually to this page, which is where you get to pay. 
You still have an internet connection so the calls from my local website that I'm hosting still get on perfectly fine so I can run our website on my laptop $100 \%$ just like I would if I was at home or at a co-work space. So I can develop with absolutely no hindrance on the flight without paying any money."

Finally, to work during commute or transit, MKWs strive to use their smartphones to their fullest potential. Several participants define their 'mobile offices' based on their smartphones. As a good example, P32, a itinerant salesman, has given up all other computing devices (even in his home office) and relies on his smartphone as the only device for emailing, running applications, and performing other work-related tasks. By untethering himself from computers, he is able to perform work during his long work commutes (a few hundred miles every week). A mobile IT support professional, P8 can similarly access clients' servers on his smartphone and fix many issues remotely while commuting between clients.

\section{Organizational Context (Organizational Resources and Constraints)}

Organizational resources and rules can both enable and constrain the technological mobility of MKWs; the effect of organizational rules, technological policies, and resources on how artifact ecologies are enacted by workers is little taken up in current research. The organization provides specific technological resources that can support mobile work practices. P27 (a digital media producer) takes advantage of a unique setup for working on the go: "We all just work from the van as somebody is driving us." Even while traveling in remote locations, she and her colleagues need to stay connected to the Internet. "They'll get a portable WiFi that will dedicate for one of the vehicles and everybody that needs to do work while we're traveling from location to location will sit in that vehicle with their laptop." The resources provided by her organization enhance technological mobility.

As a agent working for a real estate firm, P16 spends a vast majority of her working day outside of the office, but she can still draw upon multiple local offices of the firm and available desktop computers. She can access key organizational information resources from a company computer if for any reason she is not able to access them via her cell phone: "luckily the office that I work with [name of the firm], we can go to any one of our offices, it doesn't have to be our main office, so there have been times where there's actually an office where I work full time and on my lunch I'll go over there and sign in that way."

Larger organizations not only provide resources that can support mobility, but they can also impose restrictive rules and policies about the use of technologies and digital networks. These rules affect how workers can access, process, and arrange digital technologies to meet their aims and goals. They also restrict flexible enactment of technological practices, adversely influencing the mobilization of technological resources across time and space. Some MKWs therefore, weave together their own personal artifact ecologies particularly to circumvent organizational constraints. For example, they may use different computers to accomplish their work (as with P4 and P6). P4 (a knowledge management lead) often carries two different laptops because the organizational regulations restrict him from using specific software such as Google applications on his work laptop. He needs the work laptop to access the organizational resources, so he carries out his work on two parallel laptops. He uses email to transfer the needed files across the two laptops, because both cloud storage services and external drives are restricted on his work computer. He gets "this popup that says, 'You are about to send an email to an untrusted source, blah, blah, blah, do you wanna proceed?" He chooses to "override it and say 'Yes.'" because "I'm not working with anything that serious" (P4). Though this example may be quite mundane, it exemplifies a genre of strategic circumventions that many MKWs undertake in the face of organizational constraints. 


\section{DISCUSSION}

To address the first research question (what constitutes an artifact ecology), our findings present the artifact ecology around MKWs as a sociotechnical arrangement that embodies various social and contextual forces that shape the engagement of mobile workers with a broad diversity of personal computing tools, as well as organizational, and local infrastructures. This formulation of artifact ecologies goes beyond viewing them as technological phenomena (e.g., Oulasvirta \& Sumari, 2007), integrating social factors as well (see Figure 1).

This study contributes to the prior research on artifact and device ecologies-assemblages of hardware, applications, and network connections-considering how these are interwoven with context and webs of work activities. Vasiliou and colleagues (2014, p .544) argue that "the possibilities of combining information technologies in an information ecology are endless." The contextual layer highlighted here limits these possibilities, since MKWs have to constantly realign their artifact ecologies to accommodate the contextual contingencies of their work. Therefore in addressing our second research question, which concerns the influences of contextual forces, we distinguish three layers that mirror the sociotechnical fabric of the artifact ecologies enacted by MKWs. The relationship between uses of ICTs in work practices (technological layer) and various contextual forces (contextual layer) is mediated by an interpretive layer, being the ways in which MKWs interpret the context within which they operate, navigate their work activities, and know about their work practices and affordances of different technologies. Together, these three layers constitute the artifact ecologies of MKWs.

\section{The Technological Layer}

The artifact ecologies of MKWs entail a technological layer that is closely tied to work practices, as implied by the concept of sociomaterial practices (Leonardi, 2012; Orlikowski \& Scott, 2008). This layer is characterized by a large diversity of tools that support mobile work practices. Digital ecologies are produced, reinforced, and transformed in daily practices, and what binds different technologies together in them are work activities, for which multiple technologies are employed. In the formation of device ecologies, what matters is the use of technologies to support mobile work practices. Therefore, the material designs (distinctive sets of technological features) themselves do not mobilize work. The material properties of technologies only become important when MKWs employ them in their work practices. And, within the artifact ecology, affordances of each tool are relational to work practices and to that of other technologies.

This focus on work activities is in line with insights from activity-centric computing that advocates a computing paradigm supporting users' activities rather than the resources and tools used to perform such activities (Houben et al., 2014). Artifact ecologies are shaped by a web of activities (Bødker \& Klokmose, 2012) increasingly conducted across multiple devices and tools. Predominant application and device-centric design paradigms, often represented by boundaries of ecosystems (e.g., Microsoft, and Google) stand in the way of seamless interactions among various ICTs and require extra configuration work.

The multi-infrastructural environment within which MKWs operate is characterized by a lack of standardization and interoperability among competing infrastructures and ecosystems. Gateway technologies are key resources for MKWs in consolidating artifact ecologies by bringing together technologies that are not interoperable. By adopting gateway technologies, MKWs actively extend the range of the infrastructures at hand or align them to create "locally constructed gateways to globally available systems" (Jackson, Edwards, Bowker, \& Knobel, 2007, p. 370), leveraging strategic infrastructural points to form bridges or connections between separate infrastructural systems. Using these locally constructed gateways allows workers to produce artifact ecologies which "move[s] with the worker or [can be] found in the places in which the worker moves" (Davis, 2002, p. 69). 
It bears noting that much recent research on communicative devices, or artifact or device ecologies (e.g., Oulasvirta \& Sumari, 2007; Stolterman et al., 2013; Vasiliou et al., 2015) tends to concentrate on the materiality of daily devices. Stolterman and colleagues $(2013$, p. 16$)$ argue: "It seems as if an everyday intuitive way of thinking about personal interactive environments is to see them as made up by physical objects." In line with this perspective, Oulasvirta and Sumari (2007) suggest "mobile kits" to solve the problem of managing multiple devices, focusing on the physical handling of devices and cross-device synchronization. Our formulation of artifact ecology extends these ideas to include both the digital and physical environments as well as network connections around individuals. In particular, network infrastructures that may be invisible to many knowledge workers are considered "seamful aspects" of artifact ecologies in mobile work (Chalmers, 2003), since access to the Internet and networked information resources is not always given across multiple locations. Ubiquitous hardware devices, softwares, and network infrastructures constitute the artifact ecologies surrounding MKWs, embodying the intersection of virtual and physical (Yoo, 2010), and influencing the experience of mobile work. Digital technologies become increasingly embedded in the physical environments, and afford interaction across the digital-physical divide.

\section{The Contextual Layer}

As emergent sociotechnical arrangements, the device ecologies of MKWs not only embody a technological layer, but are simultaneously constituted by contextual dynamics (like personal context, the needs brought by collaboration, spatial mobility, and organizational affiliation).

Individualized artifact ecologies can become collective resources as MKWs patch together multiple systems to accommodate necessary collaborations. Personal ecologies get connected to one another, forming collaborative, distributed information spaces (Houben et al., 2014). One cannot stray out of the bounds of a shared toolset, a common digital platform, or some other socially determined sociotechnical baseline that anchors actors to one another. Even though artifact ecologies are enacted based on the personal preferences of each MKW, they also reflect a set of technologies commonly used in group collaboration with coworkers, clients, and companies. Each person is situated at the intersection of multiple artifact ecologies that undergird collaboration with multiple parties.

In addition to personal and collaborative contexts, broader contextual forces (organizational affiliations and spatial mobility) influence how our participants view and construct artifact ecologies. That is, even though MKWs may enjoy a high level of autonomy in adopting different technologies and crafting their own artifact ecology, they constantly face challenges posed by a combination of organizational policies and spatially driven resource deprivation. The artifact ecologies of MKWs have some overlap with those of other traditional knowledge workers. For example, all increasingly draw upon consumer technologies such as Dropbox or Skype, and all likely grapple with the challenges of integrating multiple device ecosystems. However, spatial mobility introduces a different set of complexities to the enactment of artifact ecologies by MKWs, and also reflects a need for mobilization work (Perry \& Brodie, 2006). MKWs in our study defined a "mobile office" (Su \& Mark, 2008; Thomson \& Jarrahi, 2015) based predominantly on an artifact ecology of hardware devices, applications, and network connections.

As implied by the term mobile, a key element of MKWs' work context is specific practices that untether them from any single location and facilitate access to resources from anywhere. With regard to our third research question, findings indicate that the spatial mobility of MKWs shapes how they configure their artifact ecologies, which are set apart from those of more traditional office workers. For example, MKWs constantly integrate local infrastructures (e.g., public WiFi networks) into their artifact ecologies. However, their nomadic work practices are impeded by local constraints and the dynamism of the mobile work context, which require active strategies that enable MKWs to work around any local constraints they encounter. 
These contextual factors can be understood as a set of rules and resources that facilitate or constrain work practices and engagement with technology (Feldman \& Orlikowski, 2011; Giddens, 1984). The ways in which workers use technologies in their work practices is in reciprocal relationship with these contextual contingences; so how they adopt and integrate multiple technologies is geared towards leveraging contextual resources and overcoming contextual constrains.

\section{The Interpretive Layer (Interpretive Schemes)}

The relationship between work context and the use of ICTs in work practices is mediated by interpretive schemes of workers, which encompass their skills, knowledge, and assumptions about technologies and their affordances for work practices (Orlikowski, 2000). In other words, interpretive schemes serve as a bridge between the technological and contextual layers in the artifact ecology around MKWs. According to Giddens (1984, p. 29), “interpretative schemes are the modes of typification incorporated within actors' stocks of knowledge," and enable actors to communicate and interpret events and actions.

Because of this interpretive layer, the artifact ecologies of MKWs reflect each worker's preferences and worldview. Even though personal ecologies share some basic characteristics, they vary based on how each individual makes sense of the ICTs available to them. Further, all are knowledgeable about choices and have some agency to shape ICT functionalities based on their knowledge, assumptions, and past experiences (Orlikowski, 1992). MKWs develop personalized understandings and meanings about how and why certain ICTs can be relevant to their mobile work practices. Each worker uses this broad understanding to address the challenges of the dynamic workplaces and associated computational situations in which they find themselves. Therefore, a certain technological acuity is a crux in MKWs' interpretive schemes (Thomson \& Jarrahi, 2015), vital for them to be adaptable to changing digital circumstances. This competency arises from a continual learning practice about different infrastructures, devices and potential disconnects among them, and engaging in improvisational workarounds that bring together multiple technologies into a cohesive and functioning personal artifact ecology.

\section{CONCLUSION}

All MKWs in this study share the experience of enacting and maintaining their needed work resources apart from any centralized organizational locus, drawing upon a wide variety of ICTs in the process. Their artifact ecologies were comprised of desktops, laptops, tablets, mobile phones, and a variety of cables and charging devices, with as many as four backup chargers. Dropbox, One Drive, Google Drive, Facebook, Twitter, LinkedIn, Hangouts, and Skype; and note-keeping and to-do list applications were also central parts of their artifact ecologies. Ubiquitous, consumerized technologies have noticeable roles here, reflecting a certain degree of autonomy and choice. However, artifact ecologies also integrate non-technological dimensions.

Our formulation of artifact ecologies goes beyond a "co-habitation of multiple heterogeneous devices that are interlinked, acting as one system" (Vasiliou et al., 2015), to see in light of four major effects. These are: technological diversity (ubiquity of personal technologies), webs of central work activities (shaping and shaped by multiple technologies), interpretive frames (personal presences and situations), and contextual forces (collaborative, organizational, and spatial). Integrating the three layers allows us to holistically capture the disparate dimensions of artifact ecologies enacted by MKWs.

Understanding mobile work and MKWs' unique technological practices can help managers who are increasingly called upon to motivate and manage mobile workforces. As our findings imply, the central concern should no longer be about maintaining 'control,' but embracing a mobile trend and taking advantage of ubiquitous computing and consumerization. However, attitude is only one half of the equation. Many 
organizations still lack the ability to adequately support and extend access to various mobile devices like iPhones, iPads, and Android devices (Kar, 2012), and risk falling behind.

Understanding MKWs' artful use of technological resources can also provide rich accounts that will help system designers to scope and improve their design spaces. As indicated, "mobile offices" are primarily defined based on MKWs' device ecologies. Most MKWs in this study and others (e.g., Lagunas, 2012) use personal devices for work-related purposes, either exclusively or in addition to company-issued devices, pointing to a widespread BYOD "bring your own device" mentality, also now supplemented by "use your own cloud" system. This requires that more attention be given to making enterprise mobility services compatible with commercial mobile devices when secure access, storage, scanning, and printing capabilities are needed (Reuters, 2012).

This research also identifies some common activities among MKWs (i.e., mobilization practices), and the ways they may construct their artifact ecologies to react to the contextual and spatial opportunities and challenges of the mobile work context. The mentality underlying the design of many technologies used by MKWs does not seem to be consistent with this ecological perspective, as it is primarily centered on a single artifact or ecosystem. This approach requires many workers to embark on extra articulation or configuration work, and employ gateway technologies or other connective strategies to bring together devices, applications or infrastructures that are not interoperable. The ecological and contextual perspective proffered in this paper helps designers to develop individual artifacts and technologies that embody mechanisms to naturally connect with other components and layers of a highly diverse artifact ecologies used by MKWs. In addition, the challenges associated with spatial mobility that our research has highlighted can also inform the design of mobile applications. Internet connectivity is not always available in the mobile work context, so workrelated applications must also offer offline functionalities.

Finally, it is important to note that the sampling approach used in this research can serve as sources of both opportunity and limitation. On the one hand, even though most participants were selected from North Carolina's Research Triangle, they represented various forms of geographic mobility observed in other studies of mobile nomadic work (e.g., Lilischkis, 2003); some participants exhibited urban mobility (e.g., those working near urban centers of Raleigh and Durham downtowns), several represented a sub-urban mobility with challenges of access to reliable digital infrastructures such as local WiFi or cellular networks (e.g. driving hundreds of miles every week within and beyond the Triangle area), and still others had other types of extensive mobility (e.g., flying out of state every week). Theorization about the three layers of artifact ecologies thus tends to hold for other mobile work contexts, explaining different aspects of the uses of multiple technologies in such work environments. With this said, we recognize that most research on the MKWs' use of ICTs has been conducted in the United States and Europe. We specifically focused on American MKWs, and even though some of our participants travelled internationally quite frequently, our findings skew towards the work contexts and digital infrastructures in the United States. Future empirical research can therefore explore other national contexts beyond the United States and even beyond Europe (e.g., in the developing world) and compare the findings.

\section{REFERENCES}

Avgerou, C. (2008). The significance of context in information systems and organizational change. Information Systems Journal, 11(1), 43-63.

Axtell, C., Hislop, D., \& Whittaker, S. (2008). Mobile technologies in mobile spaces: Findings from the context of train travel. International journal of human-computer studies, 66(12), 902-915.

Bardram, J. E. (2009). Activity-based computing for medical work in hospitals. ACM Transactions on ComputerHuman Interaction (TOCHI), 16(2), 10. 
Bardram, J. E., \& Bossen, C. (2005). Mobility work: The spatial dimension of collaboration at a hospital. Computer Supported Cooperative Work (CSCW), 14(2), 131-160.

Bardram, J. E., Jeuris, S., \& Houben, S. (2015). Activity-based computing: computational management of activities reflecting human intention. Al Magazine, 36(2), 63-72.

Barley, S. R. (1986). Technology as an occasion for structuring: Evidence from observations of CT scanners and the social order of radiology departments. Administrative Science Quarterly, 31(1), 78-108.

Barley, S. R., \& Kunda, G. (2006). Contracting: A new form of professional practice. The Academy of Management Perspectives, 20(1), 45-66.

Baumer, E. P. S., Katz, S. J., Freeman, J. E., Adams, P., Gonzales, A. L., Pollak, J., . . . Gay, G. K. (2012). Prescriptive persuasion and open-ended social awareness: expanding the design space of mobile health. Paper presented at the Proceedings of the ACM Conference on Computer Supported Cooperative Work, Seattle, WA.

Bergman, O., Beyth-Marom, R., \& Nachmias, R. (2006). The project fragmentation problem in personal information management. Paper presented at the Proceedings of the SIGCHI Conference on Human Factors in Computing Systems, Montreal, CA

Beurer-Zuellig, B., \& Meckel, M. (2008). Smartphones enabling mobile collaboration. Paper presented at the Proceedings of the 41st Annual Hawaii International Conference on System Sciences.

Blatt, K., \& Gallagher, J. (2013). Mobile workforce: The rise of the mobilocracy. In P. Bruck \& M. Rao (Eds.), Global Mobile: Applications and innovations for the Worldwide mobile ecosystem. Medford, NJ: Information Today, Inc.

B $\varnothing \mathrm{dker}$, S., \& Iversen, O. S. (2002). Staging a professional participatory design practice: moving PD beyond the initial fascination of user involvement. Paper presented at the Proceedings of the Nordic Conference on Human-Computer Interaction, Aarhus, Denmark.

Bødker, S., \& Klokmose, C. N. (2012). Dynamics in artifact ecologies. Paper presented the Proceedings of the 7th Nordic Conference on Human-Computer Interaction, Copenhagen, Denmark.

Bødker, S., Korsgaard, H., \& Saad-Sulonen, J. (2016). A Farmer, a Place and at least 20 Members' The development of Artifact Ecologies in volunteer-based Communities. Paper presented at the Proceedings of the ACM Conference on Computer Supported Cooperative Work \& Social Computing, San Fransisco, CA.

Bossen, C., \& Markussen, R. (2010). Infrastructuring and ordering devices in health care: Medication plans and practices on a hospital ward. Computer Supported Cooperative Work (CSCW), 19(6), 615-637.

Brodkin , J. (2013). How mobile technology created a workforce that never stops working. Retrieved 11 Jan, 2016 from http://arstechnica.com/information-technology/2013/08/how-mobile-technology-created-aworkforce-that-never-stops-working/

Brown, B., \& O'Hara, K. (2003). Place as a practical concern of mobile workers. Environment and planning A, 35(9), 1565-1588.

Büscher, M. (2013). Nomadic Work: Romance and Reality. A Response to Barbara Czarniawska's 'Nomadic Work as Life-Story Plot'. Computer Supported Cooperative Work (CSCW), 1-16.

Chalmers, M. (2003). Seamful design and ubicomp infrastructure. Paper presented at the Proceedings of Ubicomp 2003 Workshop at the Crossroads: The Interaction of $\mathrm{HCl}$ and Systems Issues in Ubicomp.

Chen, L., \& Nath, R. (2008). A socio-technical perspective of mobile work. Information, Knowledge, Systems Management, $7(1), 41-60$.

Ciolfi, L., \& de Carvalho, A. F. P. (2014). Work Practices, Nomadicity and the Mediational Role of Technology. Computer Supported Cooperative Work (CSCW), 23(2), 119-136.

Costas, J. (2013). Problematizing mobility: A metaphor of stickiness, non-places and the kinetic elite. Organization Studies, 34(10), 1467-1485.

Coughlan, T., Collins, T. D., Adams, A., Rogers, Y., Haya, P. A., \& Martín, E. (2012). The conceptual framing, design and evaluation of device ecologies for collaborative activities. International journal of human-computer studies, 70(10), 765-779. 
Cousins, K. C., \& Robey, D. (2005). Human agency in a wireless world: Patterns of technology use in nomadic computing environments. Information and Organization, 15(2), 151-180.

Crabtree, A., \& Rodden, T. (2008). Hybrid ecologies: understanding cooperative interaction in emerging physicaldigital environments. Personal and Ubiquitous Computing, 12(7), 481-493.

Czarniawska, B. (2004). On time, space, and action nets. Organization, 11(6), 773-791.

Czarniawska, B. (2014). Nomadic work as life-story plot. Computer Supported Cooperative Work (CSCW), 23(2), 205-221.

David, P. A., \& Bunn, J. A. (1988). The economics of gateway technologies and network evolution: Lessons from electricity supply history. Information economics and policy, 3(2), 165-202.

Davis, G. (2002). Anytime/anyplace computing and the future of knowledge work. Communications of the ACM, 45(12), 67-73.

de Carvalho, A. F. P. (2014). Collaborative work and its relationship to technologically-mediated nomadicity. Paper presented at the Proceedings of the 11th International Conference on the Design of Cooperative Systems, 27-30 May 2014, Nice (France).

de Carvalho, A. F. P., Ciolfi, L., \& Gray, B. (2011). The Making of Nomadic Work: Understanding the Mediational Role of ICTs. In M. Cruz-Cunha \& F. Moreira (Eds.), Handbook of Research on Mobility and Computing: Evolving Technologies and Ubiquitous Impacts (pp. 381-396). Hershey, PA: IGI Global.

Dearman, D., \& Pierce, J. S. (2008). It's on my other computer!: computing with multiple devices. Paper presented at the Proceedings of the SIGCHI Conference on Human Factors in Computing Systems.

Dittmar, A., \& Dardar, L. (2015). Personal ecologies of calendar artifacts. Journal of Interaction Science, 3(2), 116.

Erickson, I., \& Jarrahi, M. H. (2016). Infrastructuring and the Challenge of Dynamic Seams in Mobile Knowledge Work. Paper presented at the Proceedings of the ACM Conference on Computer Supported Cooperative Work \& Social Computing, San Fransisco, CA.

Erkut, C., \& Serafin, S. (2016). From Ecological Sounding Artifacts Towards Sonic Artifact Ecologies. Paper presented at the Proceedings of the $\mathrm{CHI}$ Conference on Human Factors in Computing Systems, San Jose, CA.

Feldman, M. S., \& Orlikowski, W. J. (2011). Theorizing practice and practicing theory. Organization science, 22(5), 1240-1253.

Fulton, C. (2005). Hotdesking: A Potential Link in the e Worker's Information Chain In J. Krogstie, K. Kautz, \& D. Allen (Eds.), Mobile Information Systems II (pp. 163-170). Berling, Germany: IFIP- Springer.

Gibson, J. (1977). The theory of affordances. In R. Shaw \& J. Bransfor (Eds.), Perceiving, acting, and knowing: Toward an ecological psychology (pp. 67-82). Hillsdale, NJ: Lawrence Erlbaum Associates.

Giddens, A. (1984). The constitution of society: Outline of the theory of structuration. Cambridge, UK.: Polity Press.

Gonzales, J. A., Fiesler, C., \& Bruckman, A. (2015). Towards an Appropriable CSCW Tool Ecology: Lessons from the Greatest International Scavenger Hunt the World Has Ever Seen. Paper presented at the Proceedings of the ACM Conference on Computer Supported Cooperative Work \& Social Computing, Vancouver, Canada.

Grinter, R. E., \& Eldridge, M. A. (2001). y do tngrs luv 2 txt msg? Paper presented at the ECSCW 2001, Bonn, Germany.

Hamilton, P., \& Wigdor, D. J. (2014). Conductor: enabling and understanding cross-device interaction. Paper presented at the Proceedings of the SIGCHI Conference on Human Factors in Computing Systems, Toronto, Canada.

Hislop, D., \& Axtell, C. (2011). Mobile phones during work and non-work time: A case study of mobile, nonmanagerial workers. Information and Organization, 21(1), 41-56.

Houben, S., Bardram, J. E., Vermeulen, J., Luyten, K., \& Coninx, K. (2013). Activity-centric support for ad hoc knowledge work: a case study of co-activity manager. Paper presented at the Proceedings of SIGCHI Conference on Human Factors in Computing Systems, Paris, France. 
Houben, S., Tell, P., \& Bardram, J. E. (2014). Activityspace: Managing device ecologies in an activity-centric configuration space. Paper presented at the Proceedings of the Ninth ACM International Conference on Interactive Tabletops and Surfaces, Dresden, Germany

Jackson, S. J., Edwards, P. N., Bowker, G. C., \& Knobel, C. P. (2007). Understanding infrastructure: History, heuristics and cyberinfrastructure policy. First Monday, 12(6).

Jarrahi, M. H., \& Sawyer, S. (2012). Social networking technologies and organizational knowledge sharing as a sociotechnical ecology. Paper presented at the Proceedings of the ACM Conference on Computer Supported Cooperative Work Seattle, WA.

Jarrahi, M. H., \& Thomson, L. (2017). The interplay between information practices and information context: The case of mobile knowledge workers. Journal of the Association for Information Science and Technology, 68(5), 1073-1089. doi:10.1002/asi.23773

Johri, A. (2011). Look ma, no email!: blogs and IRC as primary and preferred communication tools in a distributed firm. Paper presented at the Proceedings of the ACM conference on Computer Supported Cooperative Work, Hangzhou, China.

Jokela, T., Ojala, J., Grassel, G., Piippo, P., \& Olsson, T. (2015). A Comparison of Methods to Move Visual Objects Between Personal Mobile Devices in Different Contexts of Use. Paper presented at the Proceedings of the 17th International Conference on Human-Computer Interaction with Mobile Devices and Services, Salzurg, Austria.

Jokela, T., Ojala, J., \& Olsson, T. (2015). A diary study on combining multiple information devices in everyday activities and tasks. Paper presented at the Proceedings of the 33rd Annual ACM Conference on Human Factors in Computing Systems, Seoul, Republic of Korea.

Jung, H., Stolterman, E., Ryan, W., Thompson, T., \& Siegel, M. (2008). Toward a framework for ecologies of artifacts: how are digital artifacts interconnected within a personal life? Paper presented at the Proceedings of the 5th Nordic conference on Human-computer interaction Lund, Sweden.

Kar, S. (2012). Mobile Workers Present New Security Challenges for the Cloud. Retrieved 15 Jan, 2016 from http://siliconangle.com/blog/2012/04/02/mobile-workers-present-new-security-challenges-for-the-cloud/

Lagunas, K. (2012). BYOD or Bust: Survey Results Report. Retrieved 15 Jan 2016 from http://blog.softwareadvice.com/articles/hr/byod-or-bust-survey-results-report-103212/

Leonardi, P. M. (2012). Materiality, sociomateriality, and socio-technical systems: What do these terms mean? How are they different? Do we need them? In J. Kallinikos, P. M. Leonardi, \& B. A. Nardi (Eds.), Materiality and organizing: Social interaction in a technological world (pp. 25-48). Oxford Oxford University Press.

Liegl, M. (2014). Nomadicity and the Care of Place-on the Aesthetic and Affective Organization of Space in Freelance Creative Work. Computer Supported Cooperative Work (CSCW), 23(2), 163-183.

Lilischkis, S. (2003). More yo-yos, pendulums and nomads: trends of mobile and multi-location work in the information society. STAR issue report(36).

Ling, R., \& Donner, J. (2009). Mobile Communication. Cambridge:: Polity.

Ludwig, T., Dax, J., Pipek, V., \& Randall, D. (2016). Work or leisure? Designing a user-centered approach for researching activity "in the wild". Personal and Ubiquitous Computing, 20(4), 487-515.

Memarovic, N., Langheinrich, M., Rubegni, E., David, A., \& Elhart, I. (2012). Designing interacting places for a student community using a communicative ecology approach. Paper presented at the Proceedings of the 11th International Conference on Mobile and Ubiquitous Multimedia, Ulm, Germany.

Middleton, C. (2008). Do mobile technologies enable work-life balance? Dual perspectives on BlackBerry usage for supplemental work. In D. Hislop (Ed.), Mobility and technology in the workplace (pp. 209-224). London: Routledge.

Monteiro, E., Pollock, N., Hanseth, O., \& Williams, R. (2012). From artefacts to infrastructures. Computer Supported Cooperative Work (CSCW), 1-33. 
Oleksik, G., Milic-Frayling, N., \& Jones, R. (2012). Beyond data sharing: artifact ecology of a collaborative nanophotonics research centre. Paper presented at the Proceedings of the ACM Conference on Computer Supported Cooperative Work

Olson, J. S., \& Olson, G. M. (2014). How to make distance work work. interactions, 21(2), 28-35.

Orlikowski, W. J. (1992). Learning from notes: Organizational issues in groupware implementation. Paper presented at the Proceedings of the 1992 ACM conference on Computer-supported cooperative work.

Orlikowski, W. J. (2000). Using technology and constituting structures: A practice lens for studying technology in organizations. Organization science, 11(4), 404-428.

Orlikowski, W. J., \& Scott, S. V. (2008). Sociomateriality: Challenging the Separation of Technology, Work and Organization. The Academy of Management Annals, 2(1), 433-474.

Oulasvirta, A., \& Sumari, L. (2007). Mobile kits and laptop trays: managing multiple devices in mobile information work. Paper presented at the Proceedings of the SIGCHI Conference on Human Factors in Computing Systems, San Jose, CA.

Perry, M. (2007). Enabling nomadic work: developing the concept of 'Mobilisation Work'. Paper presented at the ECSCW 2007 Workshop: Beyond Mobility: Studying Nomadic Work Limerick, Ireland

Perry, M., \& Brodie, J. (2006). Virtually connected, practically mobile. In E. Andriessen \& M. Vartiainen (Eds.), Mobile Virtual Work - A New Paradigm (pp. 97-128). Berlin, Germany: Springer.

Pipek, V., Wulf, V., \& Johri, A. (2012). Bridging artifacts and actors: expertise sharing in organizational ecosystems. Computer Supported Cooperative Work (CSCW), 21(2-3), 261-282.

Rainie, H., \& Wellman, B. (2012). Networked: The new social operating system. Cambridge, MA: MIT Press.

Reuters. (2012). Ricoh tackles the challenge of mobile worker productivity. Retrieved 11 Jan 2014 from http://www.reuters.com/article/2012/09/06/idUS131742+06-Sep-2012+PRN20120906

Rossitto, C., Bogdan, C., \& Severinson-Eklundh, K. (2014). Understanding Constellations of Technologies in Use in a Collaborative Nomadic Setting. Computer Supported Cooperative Work (CSCW), 23(2), 137-161.

Santosa, S., \& Wigdor, D. (2013). A field study of multi-device workflows in distributed workspaces. Paper presented at the Proceedings of the ACM International Joint Conference on Pervasive and Ubiquitous Computing.

Sanusi, A., \& Palen, L. (2008). Of coffee shops and parking lots: Considering matters of space and place in the use of public Wi-Fi. Computer Supported Cooperative Work (CSCW), 17(2-3), 257-273.

Schultze, U. (2000). A confessional account of an ethnography about knowledge work. Management Information Systems Quarterly, 24(1), 3-42.

Sørensen, C. (2011). Enterprise Mobility: Tiny Technology with Global Impact on Work (Technology, Work, and Globalization). Palgrave Macmillan: London.

Sørensen, H., \& Kjeldskov, J. (2014). Concepts of Multi-artefact Systems in Artifact Ecologies. Paper presented at the Proceedings of 7th International Conference on Advances in Computer-Human Interaction.

Stolterman, E., Jung, H., \& Will, R. (2013). Device Landscapes: A New Challenge to Interaction Design and $\mathrm{HCl}$ Research. Archives of Design Research, 26, 7-33.

Su, N., \& Mark, G. (2008). Designing for nomadic work. Paper presented at the Proceeding of the 7th ACM conference on Designing interactive systems, Cape Town, South Africa.

Thomson, L., \& Jarrahi, M. H. (2015). Information Practices in the Broader 'Deportment' of Mobile Knowledge Work. Paper presented at the Proceedings of ASIST'15, Saint Louis, MI.

Turner, T., Qvarfordt, P., Biehl, J. T., Golovchinsky, G., \& Back, M. (2010). Exploring the workplace communication ecology. Paper presented at the Proceedings of the SIGCHI Conference on Human Factors in Computing Systems, Atlanta, GA.

Väätäjä, H. (2012). Mobile work efficiency: Balancing between benefits, costs and sacrifices. International Journal of Mobile Human Computer Interaction, 4(2), 67-87.

Vasiliou, C., loannou, A., \& Zaphiris, P. (2014). Understanding collaborative learning activities in an information ecology: A distributed cognition account. Computers in human behavior, 41, 544-553. 
Vasiliou, C., loannou, A., \& Zaphiris, P. (2015). An artifact ecology in a nutshell: A distributed cognition perspective for collaboration and coordination Human-Computer Interaction-INTERACT 2015 (pp. 55-72): Springer.

Vertesi, J. (2014). Seamful Spaces: Heterogeneous Infrastructures in Interaction. Science, technology \& human values, 39(2), 264-284.

Weiser, M. (1993). Some computer science issues in ubiquitous computing. Communications of the ACM, 36(7), 75-84.

Yoo, Y. (2010). Computing in everyday life: A call for research on experiential computing. Management Information Systems Quarterly, 34(2), 213-231.

Zhao, X., Lampe, C., \& Ellison, N. B. (2016). The Social Media Ecology: User Perceptions, Strategies and Challenges. Paper presented at the Proceedings of the SIGCHI Conference on Human Factors in Computing Systems, San Jose, CA.

\section{APPENDIX 1: SUMMARY OF THE INTERVIEW PROTOCOL}

1. What kinds of work do you do?

2. Can you describe who makes up your work-related network, inclusive of clients, colleagues, partners, and subordinates?

3. What are the types of information you need to seek to get your work done?

4. What does a typical day look like/exceptional day look like?

5. Where do you get your work done?

6. Mobility of work

[Do you work on your commute?]

[What would you do on the road?]

[What would you do in an airplane or airport lounge?]

7. What are some of the advantages to your work arrangement?

8. What are some of the challenges of your work arrangement (compared to 9-to-5 jobs)?

[How does your work affect home life? (Work-home boundaries, temporal issues, etc.)]

9. What special literacies/knowledge do you think you've developed as a mobile worker?

10. Technologies: what are the primary ones that you use? (e.g., computers, devices, peripherals; software, applications; service providers and purchased services)

[What devices and applications do you use regularly?]

[What applications do you use for task or time management?]

[Is there any company policy or expectation in relation to the use of technologies or electronic resources/networks?]

11. Internet: How do you get online?

[Do you face any problems?]

[How do you maintain the connectivity?]

[What happen if the WiFi goes down?]

[How big is your data plan on your phone?]

12. Information dealings: how do you get access to your organization's electronic resources? 
[How do you store and backup things?]

[What cloud services do you use?]

[How do you connect the digital and non-digital (e.g., paper calendar)?]

13. Social aspects of work: how do you keep yourself socially engaged with other people and make yourself visible while working independently or remotely?

[Do you attend any network event?]

[How do you connect with or keep in touch with other people?]

[Do you use social media?]

\section{APPENDIX 2: DIGITAL DIARY QUESTIONS}

1. Tell us about where you have worked so far today (or since the last diary entry). Select all that apply.

$\Gamma$ familiar public place

$\lceil$ unfamiliar public place

$\Gamma$ in transit

$\lceil$ home office
$\Gamma$ work office

ᄃ coffee shop

$\Gamma$ coworking space

$\ulcorner$ other (please fill in

2. Take a picture of the three to four most important things about the environment you're currently in (or have been in). For example, those things that help you to be productive, or prevent you from being productive.

\section{Drop files or click here to upload}

3. Please tell us what tasks/activities you have been engaged in during the last two to three hours.

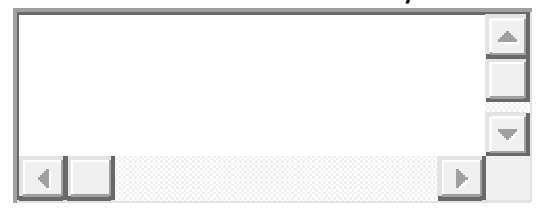

4. How have you been connected to the Internet? Select all that apply.

$\lceil$ mobile data plan

$\Gamma$ public WiFi

ᄃ private WiFi $\square$ portable WiFi router

$\Gamma$ computer tethered to phone's network connection

$\ulcorner$ other (please fill in)

5. Tell us about three important apps or softwares you have used for work so far today (or since the last diary entry).

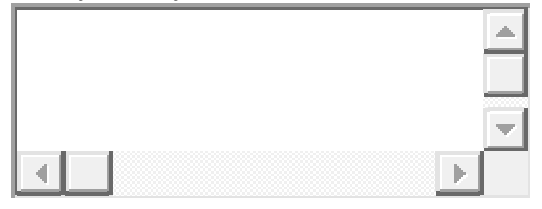


6. What devices have you used for work in the last two to three hours? Select all that apply.

Г laptop

$\lceil$ desktop computer

$\Gamma$ cell phone
$\Gamma$ tablet

$\lceil$ other (please fill in)

If relevant, take a photo of the power source you're using to charge one or more of your devices.

Drop files or click here to upload

7. What cloud services in the past two to three hours? Select all that apply.

Г Dropbox

ᄃ Google Drive

$\Gamma$ iCloud
○ OneDrive

$\Gamma$ other (please fill in)

Г None

8. Have you worked offline? If so, what activity were you engaged in?

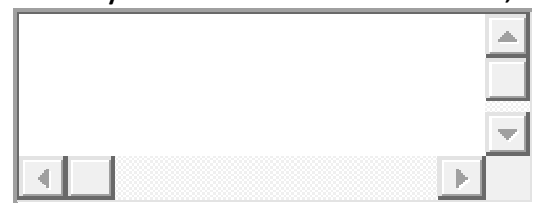

9. Have you faced any technological problems? Select all that apply.

$\lceil$ getting online

$\lceil$ accessing your work information

$\Gamma$ syncing and connecting tools and applications

10. Please elaborate on any technological problems selected in the previous question.

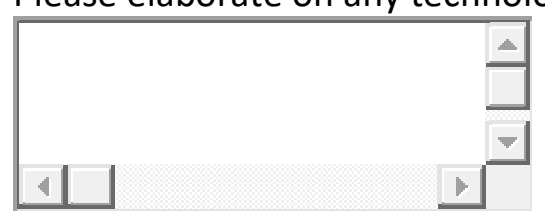

11. Whom have you met today (or since the last diary entry) for work purposes?
$\ulcorner$ clients
$\Gamma$ other (please fill in)
$\Gamma$ colleagues

12. What was your reason for talking with/meeting the people mentioned in the previous question?

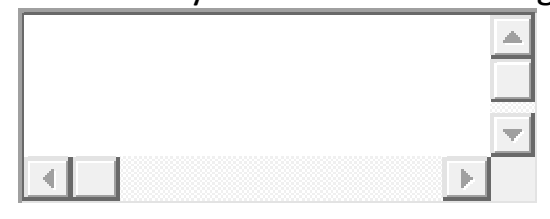


13. In what medium did you conduct your most recent conversation? Select all that apply

$\begin{array}{ll}\square \text { face-to-face } & \square \text { social Media } \\ \square \text { phone } & \square \text { chat } \\ \square \text { video conference } & \square \text { other (please fill in) }\end{array}$

14. What has been your biggest work-related challenge so far and how did you handle it?

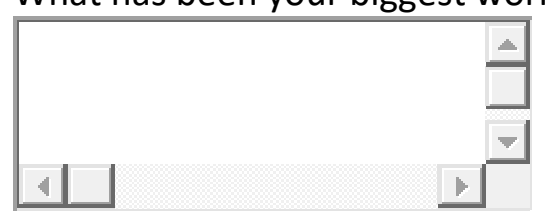

